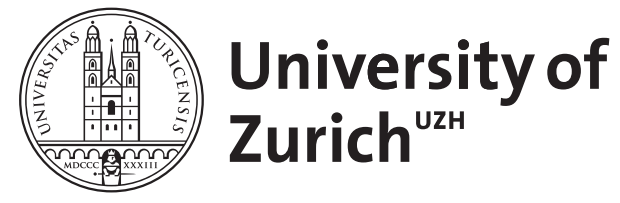
Archive

University of Zurich

University Library

Strickhofstrasse 39

CH-8057 Zurich

www.zora.uzh.ch

Year: 2012

\title{
Manipulierbare Persönlichkeit? Zur Veränderbarkeit von Charakter und Verhalten durch Tiefe Hirnstimulation
}

\author{
Müller, S ; Christen, M
}

Posted at the Zurich Open Repository and Archive, University of Zurich

ZORA URL: https://doi.org/10.5167/uzh-71297

Book Section

Originally published at:

Müller, S; Christen, M (2012). Manipulierbare Persönlichkeit? Zur Veränderbarkeit von Charakter und Verhalten durch Tiefe Hirnstimulation. In: Fink, H; Roenzweig, R. Verantwortung als Illusion. Paderborn: Mentis Verlag, 71-88. 
Helmut Fink / Rainer Rosenzweig (Hrsg.)

\section{Verantwortung als Illusion?}

mentis

PADERBORN 
Bibliografische Information der Deutschen Nationalbibliothek

Die Deutsche Nationalbibliothek verzeichnet diese Publikation in der Deutschen Nationalbibliografie; detaillierte

bibliografische Daten sind im Internet über

http://dnb.dnb.de abrufbar.

Gedruckt auf umweltfreundlichem, chlorfrei gebleichtem und alterungsbeständigem Papier @ ISO 9706

(C) 2012 mentis Verlag GmbH

Eisenbahnstraße 11, 48143 Münster

www.mentis.de

Alle Rechte vorbehalten. Dieses Werk sowie einzelne Teile desselben sind urheberrechtlich geschützt. Jede Verwertung in anderen als den gesetzlich zulässigen Fällen ist ohne vorherige Zustimmung des Verlages nicht zulässig.

\section{Printed in Germany}

Einbandgestaltung: Alexander Paul/ProSell

Satz: Rhema - Tim Doherty, Münster (www.rhema-verlag.de)

Druck: AZ Druck und Datentechnik GmbH, Kempten

ISBN 978-3-89785-814-5 


\section{Inhalt}

Vorwort

Helmut Fink

Einleitung: Alternativlose Schuld?

Gerhard Roth

Strafe oder Therapie? - Über einen menschenwürdigen

Umgang mit Gewaltstraftätern

Hans J. Markowitsch, Angelica Staniloin

Gehirn und Gewalt - Der determinierte Täter

Sabine Müller, Markus Cbristen

Manipulierbare Persönlichkeit? - Zur Veränderbarkeit

von Charakter und Verhalten durch Tiefe Hirnstimulation .. 71

Grischa Merkel

Motive, Gründe und Ursachen für strafbares Verhalten -

Kriterien eines »Kernstrafrechts«?

Boris Kotchoubey, Niels Birbaumer

Lernen von Freiheit - In welchem neurobiologischen Sinne

können Handlungen frei und verantwortlich sein?

Ansgar Beckermann

Gehirn und Freiheit

Peter Janich

Die Sprache der Hirnzauberlehrlinge -

Über den Sitz der Verantwortung

Marco Stier

Keine Illusionen! - Über die Grenze der Verantwortung ohne Willensfreiheit

Hans-Ludwig Kröber

Kriminalprognose an hirndeterminierten

Rückfallautomaten? - Über die Freiheit des Verbrechers 
Adelheid Kastner

Wert, Sinn und Zweck des Normativen -

Willensfreiheit aus forensisch-psychiatrischer Sicht

Glossar .

201

Die Autorinnen und Autoren 